\title{
Cottage cheese products from concentrated raw materials
}

\section{Editorial}

In Russia dairy products consume on daily basis. For it production we need complex of equipment for carrying out technological processes. Thus we studied the possibility of using existing equipment to produce cottage cheese and cheese products from concentrated raw materials, and the proposed technological line, which can be used at the enterprises of the dairy industry.

In addition to the cottage cheese on this technological line can be manufactured cheese products, curd desserts, curd paste, curd, dairy desserts and other concentrated dairy products by varying the ratios of the compounding components and the degree of evaporation of the milk mixture.

Technological lines of dairy products are widespread, mainly for cheese making. Such technological lines include milk acceptance and preparation area, a cottage cheese tub, means for separating whey, chiller and mixer with a device for supplying the filler. Such lines allow produce high-quality concentrated milk products, mainly cheese. But we lost part of components (dry solids) of raw milk: whey have significant amount of protein and fat, a significant part of the milk sugar and salts. Also the products obtained do not have varied organoleptic characteristics.

A large number of technological lines for cheese products with various fillers exist. For example, in Russian patent № 43121 technological line of dairy products, mainly cheese, described. The line include milk acceptance and preparation area, a cottage cheese tub, means for separating whey, cooler, mixer equipment for preparing, chopping and serving filler, provided with a device for drying of the filler. This allows adding in concentrated dairy products a wide range of fillers, in particular, fillers requiring preliminary grinding and/or drying, and obtaining dairy products with varied organoleptic characteristics.

Nevertheless such lines contains a means for whey separation and presupposes the existence of the technological process of whey separation, and hence the loss of raw milk components along with the whey. Thus final product significantly reduces chemical value, potentially presented in raw materials. In addition, the separation of the whey is laborious and time-consuming operation.

The author set as objective the creation of technological line for cottage cheese products which would full use of raw milk dry matter, while getting the finished products with a wide range of organoleptic properties, as well as to minimize the whey separating process.

To solve this problem technological line for cottage cheese supplied vacuum-evaporating apparatus associated with a cottage cheese tub.

The supplying of the technological line with vacuum-evaporating apparatus enables to thicken raw milk and evaporate significant portion of the water to provide the necessary concentration of dry substances. Adjusting the degree of evaporation is possible for a wide range of

\author{
Volume 6 Issue I - 2017
}

\author{
Olga Musina \\ Department of Analyses, Altai State Technical University, Russia
}

Correspondence: Olga Musina, Head of the Scientific

Information' Analyses Department Siberian Research Institute of Cheese-Making, Institute for Biotechnology, Food and Chemical Engineering at Altai State Technical University, Russia, Email musinaolga@gmail.com

Received: December 15, 2016 | Published: February 06, 2017

concentrated products from raw milk: condensed beverages, cheese products, intermediate between the consistency, dairy spreads, cheese products, etc. It is important that by evaporation the concentration of raw milk increases, and amount of whey reduces (to zero depending on the type of final product), i.e. the components of raw milk used better, its dry solids are almost completely remain in the final product. Furthermore, the use of concentrated milk can significantly reduce the duration of the process of separating the whey by reducing its amount, until it is not necessary to separate the whey, depending on the final product.

Technological line for cottage cheese products from concentrated raw materials is schematically depicted in Figure 1.

The line includes the milk acceptance and preparation area (not shown), consisting of the traditionally used units: the milk container, pump, separator-milk cleaner; a vacuum-evaporating apparatus

\section{i. a cottage cheese tub}

ii. a means to separate the whey

iii. a cooler

iv. a mixer

v. with a device for supplying the filler

vi. a chopper

vii. and device for drying of the filler

viii. All units are connected by piping

ix. with shut-off and control valves (not shown)

As the vacuum-evaporating apparatus 1 can be used device, allowing to thicken raw milk in the shortest time at a temperature of 50-55 Celsius, increasing it at the end of condensation up to $55-60^{\circ} \mathrm{C}$, for example a vacuum apparatus with the heating surface in the form of a tubular or plate heat exchanger. 


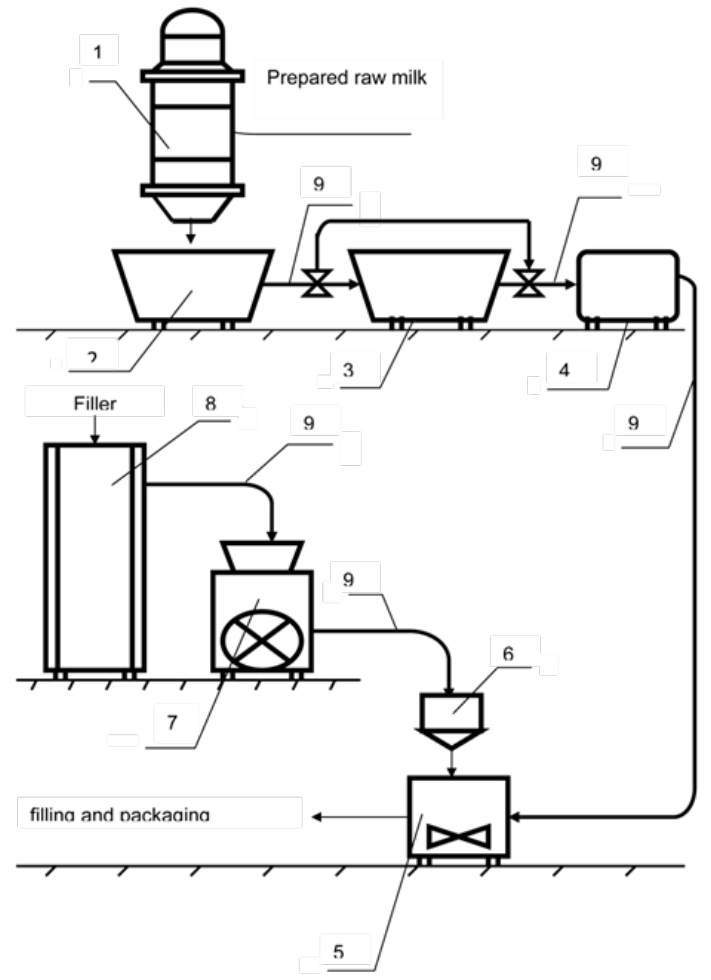

Figure I Technological line for cottage cheese products from concentrated raw materials.

The technological line for cottage cheese products works as follows.

Raw milk comes to acceptance and preparation area (not shown), where it undergoes processing in accordance with one of the known technologies. Then prepared raw milk enters into the vacuum-evaporating apparatus 1 , where it is thickened to the desired concentration of solids. Further condensed raw milk arrives in the cheese tub 2, There we add the starter, milk-clotting enzyme, calcium chloride and/or other components for fermentation. Raw milk is mixed and leaved for fermentation. To obtain a more concentrated milk product by fermentation, a curd is pumped through the pipeline 9 into a means for separation of whey 3 , where additionally separate the whey. The whey is withdrawn for reservation and a cottage cheese curd fed in a cooler 4 .

It is possible to obtain concentrated dairy products that do not require whey separating, which is produced by the greater evaporation of raw milk. In this case after the vacuum-evaporating apparatus all raw milk fermenting forming a whole protein-carbohydrate-fat matrix.

From the cooler 4 concentrated dairy product is fed to a mixer 5 with a device for supplying the filler 6 . The filler, if necessary, enters the device for drying 8 , and passing the chopper 7 as fine particles also enters the mixer 5 with a device for supplying the filler 6 . All components are mixed until a homogeneous mixture and are directed to filling and packaging.

Thus, supplying the line with the vacuum-evaporating apparatus gives chance to save the components of raw milk in cheese products, and to give them a different organoleptic property, and also significantly reduce the amount and duration of the process of separation of the whey by reducing its quantity.

\section{Acknowledgements}

None.

\section{Conflict of interest}

Author declares that there is no conflict of interest. 